\title{
Projeto de uma impressora $3 d$ de baixo custo utilizando o Arduino mega 2560
}

\author{
Maria Valéria L. da C. Almeida ${ }^{[1]}$, Taciano Amaral Sorrentino ${ }^{[2]}$, Antônio Gomes Nunes ${ }^{[3]}$ \\ [1] Universidade Federal Rural do Semi-árido; leralimeira@ gmail.com \\ [2] Universidade Federal Rural do Semi-árido; taciano@ufersa.edu.br \\ [3] Universidade Federal Rural do Semi-árido; nunesag@ufersa.edu.br \\ Recebido: $12 / 07 / 2019$; \\ Aceito: 22/07/2019; \\ Publicado: 07/10/2019.
}

Resumo: A ideia da construção de uma impressora 3D surgiu dos integrantes do projeto de pesquisa Codificações Orientadas ao Desenvolvimento Eletrônico (CODE) da Universidade Federal Rural do Semi-Árido, quando sentiu a necessidade de inclusão de uma tecnologia útil e inovadora no ambiente acadêmico. Assim, com o auxílio do grupo em trabalhos laboratoriais e pesquisas bibliográficas tornou-se possível a construção da impressora, o único empecilho considerado seria o custo, pois o projeto não era financiado, necessitando utilizar métodos para reduzir os gastos ao máximo. Entretanto, uma série de complicações não consideradas inicialmente surgiram durante a preparação e execução do projeto, principalmente pelos recursos limitados, atrasos na entrega dos componentes e eventuais obstáculos ao decorrer da construção. Esses fatores, fizeram com que a impressora não estivesse funcional no tempo estipulado, porém, conseguiu-se chegar em um estágio de avanço considerável, alguns testes de calibração foram feitos e bem-sucedidos, porém alguns problemas surgiram e atualmente ela está em fase de estudo dos componentes para identificar aqueles que estão danificados e os motivos que ocasionaram esses danos. Apesar do projeto não ter sido finalizado, diversos conhecimentos foram necessários para resolver os impasses que foram surgindo, e para utilização do mínimo de recursos possíveis sem alterar a eficiência da mesma.

Palavras-chave: Prototipagem Rápida. Impressora 3D. Inovação. Construção. Arduino.

\section{INTRODUÇÃO}

\begin{abstract}
$\mathrm{A}$ impressora tridimensional (3D) é um dispositivo de prototipagem rápida utilizado para imprimir ou criar objetos em três dimensões. O seu funcionamento se dá através da partição do objeto em fatias e deposição camada por camada [1]. Devido a sua praticidade e sua gama de aplicações, a impressora 3D vem se tornando um dispositivo que auxilia no âmbito acadêmico e que cada vez mais é desejada por estudantes e entusiastas em tecnologia. Contudo, apesar de ser uma tecnologia bastante futurística, a impressora 3D não é uma invenção recente, ela foi criada por volta de 1984 por um norte-americano chamado Chuck Hull. No início, a impressora utilizava a técnica de estereolitografia [2], porém, a mais utilizada atualmente é a FMD (Modelagem por Fusão e Deposição) devido ao seu preço inferior e maior facilidade de uso em relação às demais. Apesar de terem se passado mais de 30 anos da descoberta dessa tecnologia ainda hoje o seu valor de mercado não é acessível à maior parte da população.
\end{abstract}

Diversas técnicas de impressão tridimensional e modelos de impressoras foram criadas ao longo desses anos, elas variam em preços e poder de impressão. Podem ser encontrados no mercado desde modelos mais simples, como os fabricados pela Metamáquina que custam por volta de três mil reais, até modelos mais robustos e poderosos como a Multi Jet Fusion da HP® que possui velocidade de impressão dez vezes maior que outros modelos da $\mathrm{HP} ®$ e é capaz produzir até três objetos de uma só vez, contudo, seu valor de mercado chega a mais de oitocentos mil reais [3]. 
Os maiores empecilhos na aquisição de uma impressora tridimensional, é o seu alto custo e a falta de conhecimento adequado para a utilização da mesma. Visando baratear tal dispositivo, o projeto de pesquisa CODE (Codificações Orientadas ao Desenvolvimento Eletrônico), da Universidade Federal do Rural do Semi-Árido, resolveu utilizar conhecimentos técnicos em engenharia aliados à necessidade da inserção de novas tecnologias na Universidade, para construir uma impressora 3D do tipo Stella. Utilizando a programação da plataforma Arduino®, objetivando a incrementação da impressora 3D na Universidade. Auxiliando na didática dos docentes ao ministrar as disciplinas por meio da prototipagem de objetos concretos que ajudam na visualização do conteúdo transmitido.

O Arduino® é uma plataforma de código aberto, isto é, que pode ser usada e modificada por qualquer usuário, no qual é possível interagir softwares com hardwares, programando e criando circuitos eletrônicos de acordo com a disponibilidade de componentes e o projeto a se construir [4]. O tipo de Arduino® mais utilizado é o UNO, ele possui 14 pinos de entrada e saída. Além desse existe diversos outros tipos de Arduino®, que são utilizados de acordo com a necessidade do projetista. Desta forma, a presente pesquisa objetiva o projeto e a construção de uma impressora 3D utilizando materiais alternativos com a utilização do Arduino® Mega 2560, que tem uma memória maior e uma maior quantidade de pinos que o UNO, e a integração dessa tecnologia na Universidade. Além disso, trabalhos laboratoriais foram realizados para a montagem e testes da impressora. O projeto será subdivido em quatro etapas para melhor entendimento da construção: montagem mecânica, eletrônica, extrusora e configuração dos softwares. Também foi abordada as dificuldades encontradas durante a montagem, funcionamento e estágio atual da impressora, já que sua conclusão não foi possível no tempo pré-determinado.

\section{IMPRESSÃO TRIDIMENSIONAL}

A impressão 3D baseia-se em criar protótipos de produtos de forma rápida e eficiente através de uma impressora de prototipagem rápida. Ela tem uma grande vantagem por ser precisa na criação de objetos e dispensar a utilização de ferramentas [5]. Essa tecnologia está sendo cada vez mais utilizada principalmente por empresas e indústrias, e vem ganhando destaque no mercado. É notório o avanço nos estudos das técnicas de impressão tridimensional que tornam essa tecnologia cada vez mais inovadora e próxima à realidade de estudantes do ensino público [6].

\subsection{Histórico}

Por volta de 1984, foi descoberta por Chuck Hull nos Estados Unidos, uma tecnologia capaz de criar objetos em três dimensões com um alto nível de praticidade. Apesar de ter sido descoberta em 1984, a primeira impressora só foi comercializada 3 anos depois, ou seja, em 1987 pela empresa 3D Systems®, em que era utilizada a técnica de estereolitografia, que consiste no uso de luz ultravioleta para curar polímeros fotossensíveis [7]. O polímero líquido fica dentro de uma cuba contendo uma plataforma perfurada logo abaixo do nível do líquido, assim, o laser atinge a fina camada de fluido nos pontos a serem solidificados, formando a primeira camada e a repetição deste processo forma o objeto. No mesmo ano em que a SLA-250 foi lançada, a empresa Scott Scrump lançou a técnica chamada de Modelagem por Fusão e Deposição (FDM), sendo a técnica mais utilizada atualmente. Ela consiste na fusão de um filamento e a deposição camada por camada até formar o objeto. Os materiais utilizados na deposição podem ser dos mais diversos: plástico, chocolate, concreto, metal, entre outros; porém, os mais comuns são plásticos como ABS (Acrilonitrila Butadieno Estireno) e PLA (Plástico de Poliácido Láctico) [1]. Atualmente existe uma infinidade de técnicas e modelos de impressoras que tentam suprir as necessidades do mercado consumidor.

\subsection{Aplicações da impressão tridimensional}

A impressora 3D possui uma gama de aplicações, pode ser utilizada desde uso doméstico até empresas de grande porte. Das diversas áreas de aplicação podemos destacar o auxílio didático de professores em sala de aula, a construção civil e a medicina. No âmbito acadêmico, apesar de ser um acessório bem útil, faltam incentivos e literaturas que tratem sobre essa aplicação. Foi comprovado que no uso da impressora 3D, 
ocorreram situações estimuladoras ao aprendizado durante as construções e que ela pode colaborar com o desenvolvimento da didática para o Ensino de Ciências [8].

Na construção civil, a impressão 3D é utilizada através de 3 principais tecnologias. A primeira é a Contour Crafting, que utiliza a fabricação aditiva formando estruturas de materiais cerâmicos e à base de cimento. A segunda é a Concrete Printing, que utiliza um sistema baseado em extrusão tradicional e imprime partes a base de cimento. A terceira é a D-Shape, que consiste na deposição de pó endurecido através da aplicação local de um material ligante [9]. Já na medicina, a impressora 3D vem auxiliando em vários campos, na elaboração de novas abordagens terapêuticas, e na dinamização de procedimentos cirúrgicos, o que garante um melhor prognóstico e qualidade de vida para os pacientes. Hoje é possível construir órgãos, tecidos, próteses, entre outras utilizações, porém a maior limitação é o custo que é bastante elevado [10].

\subsection{Impressora $3 d$ Stella}

A Stella é uma impressora 3D brasileira compacta e com melhor preço do mercado custando $\mathrm{R} \$ 1.920,00$, em dezembro de 2018, não tendo nenhuma concorrente na mesma faixa de preço. Apesar de ser compacta, ela possui uma boa área de impressão, já que sua base se move em um eixo (Y) e a cabeça de impressão em dois eixos (X e Z) como mostra a Figura 1 [11].

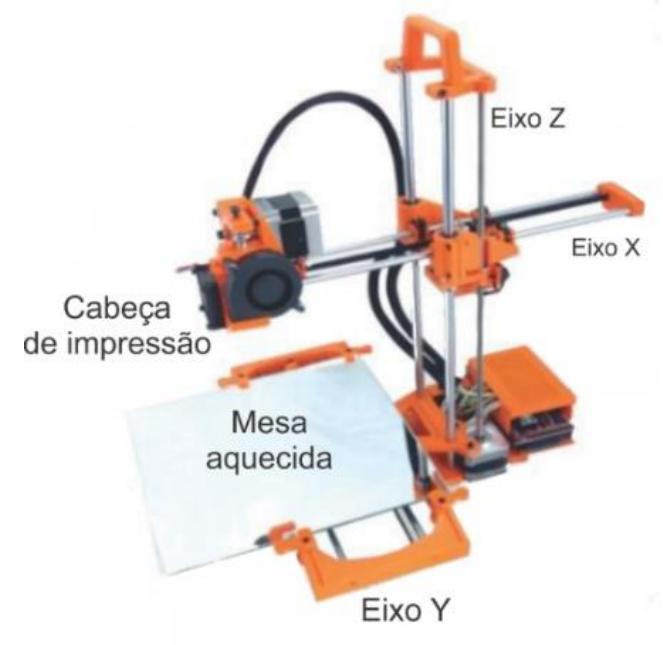

FIGURA 1. Impressora 3D Stella. [12]

\section{ARDUINO®}

O Arduino® é uma plataforma de microcontrolador de código aberto, fácil uso e baixo custo, que possui um plugue de conexão USB que permite a ligação com um computador. Devido a sua facilidade de uso e natureza aberta, ela serviu de incentivo para auxiliar nos estudos que envolvem a eletrônica [4]. O Arduino® possui linguagem de programação própria bastante semelhante a linguagem $\mathrm{C}++$, sendo visto como uma vantagem para a maioria do seu público alvo que já possui o conhecimento nessa linguagem de programação.

\subsection{Arduino® Mega}

O Arduino® Mega mostrado na Figura 2, é destaque entre as placas Arduino®, apesar de não ser o mais usado no mundo, ele possui uma alta performance devido aos seus conectores extras colocados em um dos lados da placa. Ele usa o processador ATmega1280 que é fixo na placa, não sendo possível a substituição, as suas demais especificações estão descritas na Tabela 1. Normalmente, esse Arduino® Mega é utilizado em projetos mais complexos e que exigem um maior número de componentes integrados a ele, além disso conta com uma maior quantidade de memória do que o UNO [4]. 
TABELA 1. Especificações Arduino® Mega. (Autoria própria)

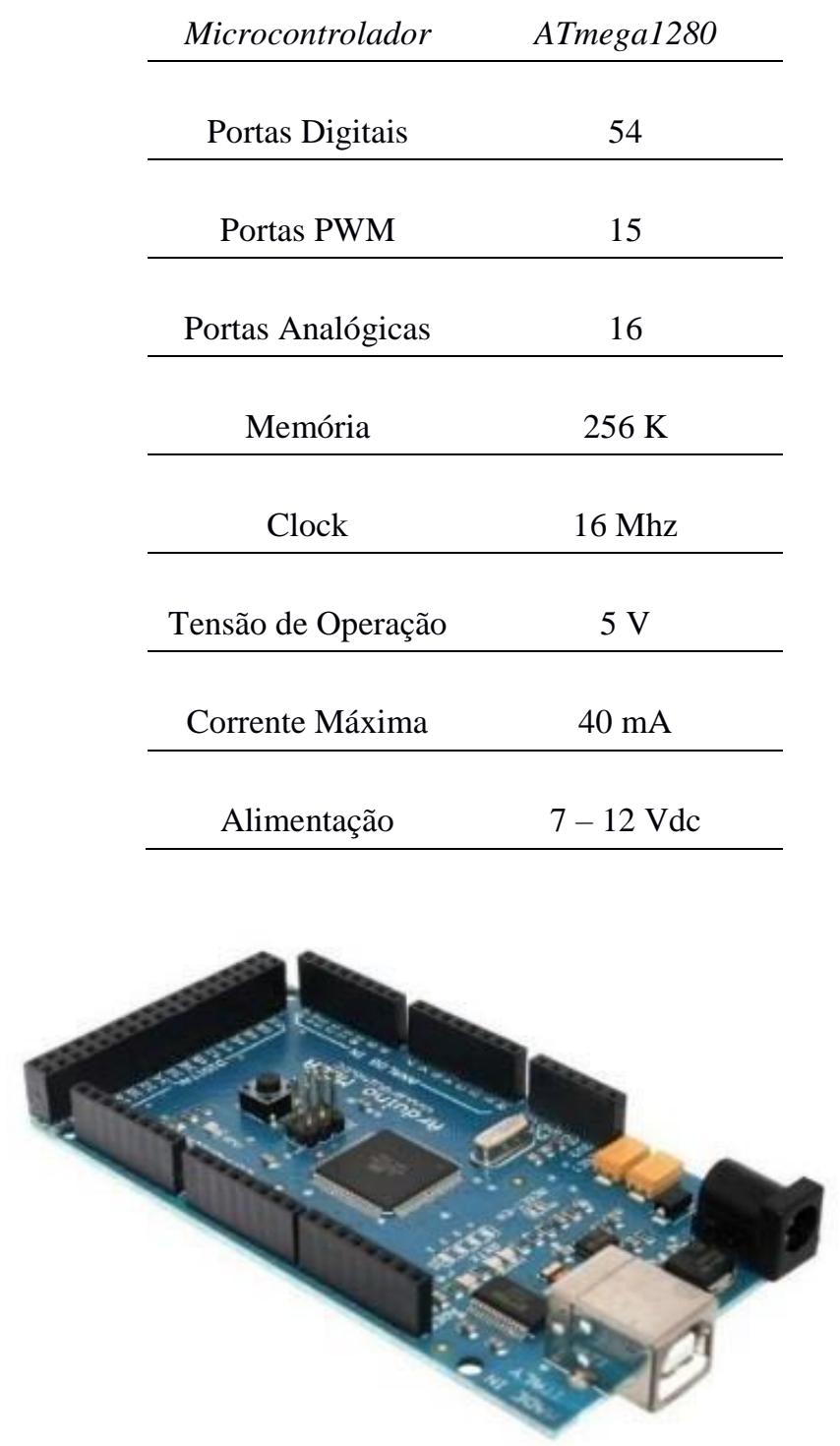

FIGURA 2. Arduino® Mega. [13]

\subsection{Shields}

As Shields são placas acessórias compatíveis com o Arduino®, encaixadas diretamente em cima da placa, que dispensam o uso do ferro de solda [4]. Elas são muito úteis principalmente para projetos mais elaborados, pois não deixam o Arduino® sobrecarregado de fios e componentes ligados diretamente a ele.

\section{REDUÇÃO DE CUSTO EM TECNOLOGIAS}

Os custos dos equipamentos muitas vezes são uma das principais barreiras para a implementá-los nas universidades ou em qualquer setor, público ou privado. Contudo, segundo Castro e colaboradores [14], os custos são essenciais para o desenvolvimento de qualquer mecanismo.

Atualmente, o uso das novas tecnologias vem se intensificando cada vez mais nas escolas e nas universidades. A introdução de novas tecnologias nas salas de aula possibilita ao aluno ver o futuro e tornam as aulas mais atraentes [16].

\subsection{Custos das tecnologias}


Os custos são gastos essenciais para a produção de um produto, pois os fatores produtivos dependem desses custos. A tecnologia é uma ferramenta indispensável para os diversos segmentos sociais, pois é com ela que se consegue desenvolver melhor algumas atividades diárias [14].

A implementação das novas tecnologias nas organizações como empresas e nas universidades muitas vezes é um empecilho para o aprimoramento do processo produtivo ou para o desenvolvimento acadêmico. Como pode ser observado no caso da impressora 3D, que ainda não é implementada nas instituições principalmente devido ao seu alto custo. Contudo, parcerias entre as empresas e as universidades são feitas para a redução dos custos.

\subsection{Ferramenta pedagógica}

A ferramenta pedagógica tem um significado amplo, pois o profissional pode utilizar qualquer método, desde que facilite a compreensão do aluno e que sirva de melhoria para o processo educacional. O computador tem sido utilizado tanto para ensinar quanto para a prática individual. Contudo, a impressora 3D também funcionaria da mesma forma, pois tanto ajudaria na soma de conhecimentos dentro de sala, para auxílio na visualização da teoria repassada, quanto para a utilização individual [17].

\section{MATERIAIS, MÉTODOS E CUSTOS}

Para a construção da impressora inicialmente foram necessárias pesquisas bibliográficas para embasar a ideia inicial, a partir da leitura de livros e artigo foi que pôde ser feita a lista de materiais necessários mostrada na Tabela 2. Após a avaliação dos preços através de pesquisas em diversos sites de venda na internet, ficou constatado que a melhor opção seria o AliExpress ${ }^{\circledR}$ Online Shopping, uma loja virtual internacional, desta forma, sujeito a taxação, atraso na entrega e até mesmo defeito no produto. Esses diversos fatores causaram um atraso já no início da construção.

TABELA 2. Orçamento da construção da impressora 3D, agosto de 2018. (Autoria própria)

\begin{tabular}{|c|c|c|c|}
\hline LISTA DE MATERIAIS & QUANT. & $P R E C ̧ O R \$$ & LOCAL DE COMPRA \\
\hline $\begin{array}{l}\text { Pregos parafusos e materiais diversos (madeira, } \\
\text { alumínio) }\end{array}$ & - & 45,00 & Lojas locais \\
\hline Arduino Mega 2560 & 2 & \multirow[b]{3}{*}{80,00} & \multirow[b]{3}{*}{ Aliexpress } \\
\hline RAMPS 1.4 & 1 & & \\
\hline Controle de passos A4988 & 4 & & \\
\hline Motor de passos 28BYJ-48 5V & 4 & 35,00 & Aliexpress \\
\hline Fonte de alimentação $12 \mathrm{~V}, 10 \mathrm{~A}$ & 1 & 47,85 & Aliexpress \\
\hline Polia GT2 20 dentes /diâmetro i = 5mm & 2 & \multirow[b]{2}{*}{15,50} & \multirow[b]{2}{*}{ Aliexpress } \\
\hline Correia GT2 $0.5 \mathrm{~m}$ T25 & 1 & & \\
\hline Rolamento 624ZZ 13 x 5 x 4mm & 2 & 7,84 & Aliexpress \\
\hline Rolamento LM8UU 15x 24x 8mm & 12 & 18,28 & Aliexpress \\
\hline Haste lisa D8 250mm 8mm & 6 & 77,6 & Lojas Locais \\
\hline Haste roscada M5 250mm 5mm & 1 & 16,29 & Aliexpress \\
\hline Chave Fim de curso & 3 & 16,62 & Aliexpress \\
\hline Hot end E3D V5 1.75mm (filamento) 0.4 nariz & 1 & \multirow[b]{3}{*}{30,00} & \multirow[b]{3}{*}{ Aliexpress } \\
\hline Cooler do Hot end E3d V5 & 1 & & \\
\hline Tubo de Teflon De $=4 \mathrm{~mm}$ Di=3mm , $1 \mathrm{~m}$ & 1 & & \\
\hline Cooler 12V 30x 30x 10 mm & 2 & 11,02 & Aliexpress \\
\hline Engrenagem extrusor MK8 & 1 & 1,87 & Aliexpress \\
\hline Hot Bed & 1 & \multirow[b]{2}{*}{30,00} & \multirow[b]{2}{*}{ Aliexpress } \\
\hline Termistor para a hot bed & 1 & & \\
\hline Filamento $1.75 \mathrm{~mm}$ ROLO & 1 & 20,00 & Aliexpress \\
\hline Bucha 8mm (Para a haste) & 12 & 19,55 & Aliexpress \\
\hline Abraçadeiras (pacote) & 2 & 15,65 & Aliexpress \\
\hline Abraçadeiras metálicas & 4 & 15,00 & Lojas Locais \\
\hline Molas para a hot bed (Maior que o parafuso) & 4 & 6,32 & Aliexpress \\
\hline
\end{tabular}




\begin{tabular}{lccc}
\hline Acoplador Flexível & 2 & 15,51 & Aliexpress \\
\hline Regulador de tensão & 1 & 6,00 & Aliexpress \\
\hline TOTAL & - & 503,90 & - \\
\hline
\end{tabular}

Com o intuito de adquirir conhecimento a respeito de um problema e buscar respostas ao qual se quer experimentar, tal pesquisa pode ser caracterizada como descritiva ou experimental, de acordo com Ada Magali Brasileiro [18]. As pesquisas foram feitas em etapas, estudando separadamente e analisando os fatores diversos que influenciam de forma direta no custo da tecnologia. Também foram feitos testes e experimentos com o Arduino ${ }^{\circledR}$ analisando a melhor e mais didática forma de utilizá-lo em substituição dos circuitos de alto custos empregados nas impressoras $3 \mathrm{D}$ comerciais.

\subsection{Construção da impressora $3 d$}

Pensando em facilitar o trabalho braçal e redução de custos foi escolhida a impressora do tipo Stella, por ser mais compacta e não ter tantas peças estruturais. $O$ projeto foi dividido em 4 etapas, visando diminuir a complexidade: a mecânica (montagem da base, suportes e movimentos), a eletrônica (toda parte de conexões de fios e ligação dos componentes com o Arduino ${ }^{\circledR}$ ), a extrusora (responsável por guiar em direção a ponta aquecida) e a parte de softwares (programas computacionais e os códigos).

\subsubsection{Mecânica}

Diversas peças formam a estrutura da impressora 3D, a Figura 3 mostra todas essas peças que foram utilizadas para a parte mecânica e estrutural. As partes de sustentação e movimento são os apoios e suportes de madeira (A), que estão com suas dimensões representadas no Apêndice 1; hastes de aço inox (B) e componentes responsáveis pelo movimento da hot end (C) (encarregado pela fusão do filamento para a impressão) que se movimenta nos eixos X e Z, e da hot bed (D) (aquece de acordo com a programação para a fixação do filamento na superfície, além disso, deixa o material na temperatura adequada para a modelagem das peças) que se movimenta no eixo Y. Para que ocorra esse movimento dos eixos são utilizadas correias (E), buchas (F) (por onde as hastes deslizam), polias dentadas (G) e o acoplador flexível (H), responsável pelo movimento do eixo $\mathrm{Z}$, ele conecta a haste roscada (I) com o motor de passo e não se rompe quando é tensionado. É de suma importância a utilização das peças estruturais de madeira na impressora 3D por ser de fácil moldagem e ter uma resistência boa. Foi necessário fazer ajustes nos apoios das hastes para melhor colocação das braçadeiras metálicas que tensionam as correias.

O rolamento (J) é outro material de extrema importância, pois ele facilita a propagação de tensão de um sentido para o outro, sem prejudicar no movimento. Também temos as abraçadeiras plásticas e metálicas $(\mathrm{K})$ plásticas e metálicas que fixam as buchas e as correias respectivamente, parafusos e porcas que conectam os componentes nos seus devidos lugares. Os posicionamentos dos componentes na impressora 3D foram escolhidos de forma a facilitar ao máximo a movimentação dos eixos e torná-la a mais eficiente possível. Para que ocorra os movimentos de todos os eixos e da extrusora, é necessária a inserção de um componente indispensável que são os motores. Os motores normalmente utilizados para esse fim são os do tipo Nema 17, porém, eles não possuem um preço baixo e a escolha deste tipo de motor aumentaria consideravelmente o preço do projeto. Então, pensando nisso, foi feita uma adaptação do motor de passo 28BYJ-48 5V (L) passando de unipolar para bipolar para que ele possa realizar as operações de um motor convencional. Os movimentos dos eixos $\mathrm{X}$ e Y se dão através da rotação das polias dentadas conectadas aos motores de passos, que movem a correia fazendo as buchas deslizarem nas hastes. Já o movimento do eixo $\mathrm{Z}$ acontece pela rotação do acoplador flexível através do motor de passo, rotacionando a haste roscada que está conectada no eixo $\mathrm{X}$ por uma porca, e a medida que a haste rotaciona uma altura é incrementada. 


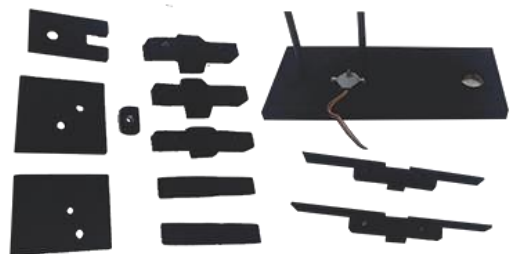

(A)

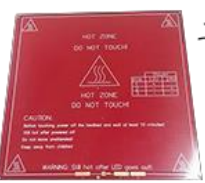

(D)

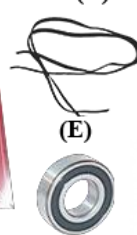

(J)

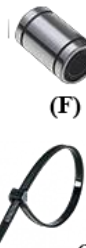

(K)

(F)

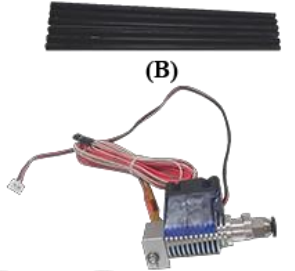

(C)

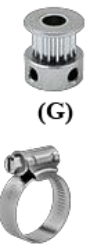

(G)

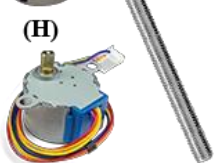

(L) (I)

Figura 3. Partes Mecânicas da impressora 3D. (A, B, D, E, G, H, I - Autoria Própria; F - [19]; J - [20]; K [21])

\subsubsection{Extrusora}

A extrusora, mostrada na Figura 4, é responsável por ejetar o filamento em direção ao hot end. Ela é formada por um motor de passo conectado a uma engrenagem, que com o auxílio de um rolamento, empurram o filamento pelo tubo teflon até que chegue à parte de aquecimento, onde será fundido e depositado sobre a hot bed. O esquema da Figura 4 esclarece melhor o funcionamento da extrusora.
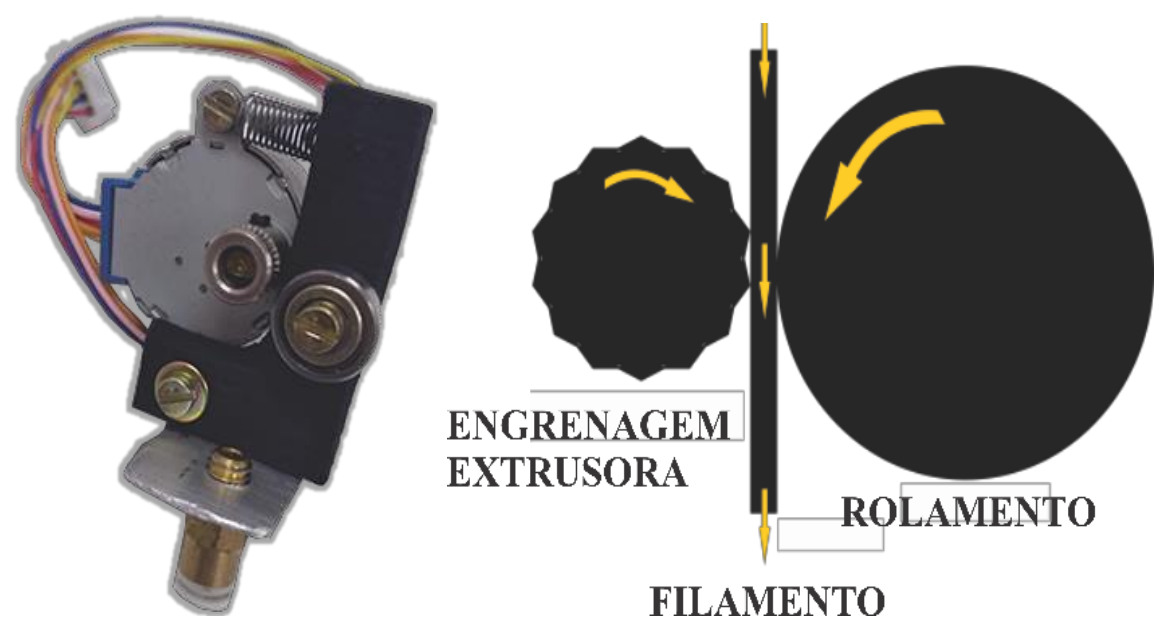

FILAMENTO

FIgURA 4. Extrusora e esquema de funcionamento. (Autoria Própria)

\subsubsection{Eletrônica}

A eletrônica engloba todo controle e circuitos montados para que haja o funcionamento da impressora, o Arduino® Mega 2560 é o controlador que recebe os códigos e repassa para os demais componentes que formam o circuito. Na Figura 5, é mostrado o esquema de montagem do circuito eletrônico sobre a RAMPS 1.4, que é uma shield onde os componentes eletrônicos necessários para a impressora serão conectados. Como o Arduino® sozinho não consegue alimentar a impressora, então foi adicionado uma fonte de $12 \mathrm{~V}$ e $10 \mathrm{~A}$. O movimento nos eixos é realizado por motores de passos controlados através de um dispositivo chamado controle de passos A4988 que conta com dispositivo de dissipação de calor para que o Arduino não exceda a sua temperatura máxima de funcionamento. Tem-se também os chamados fim de curso que são responsáveis por delimitar a área de impressão, ele mostra até onde a hot end pode percorrer na haste, além disso, os fins de curso servem como um sistema de proteção, pois se houver algum erro de distanciamento no software, quando a hot end chegar no limite ocorrerá o desligamento dos motores. Para melhor controle de temperatura um 
cooler é acoplado na hot end. Além de tudo isso, um componente de grande importância é o termistor, principalmente por estar se tratando de controle de temperatura na hot end e na hot bed, os dados enviados pelo termistor podem ser lidos pelo Arduino® e apresentados ao usuário para ajudá-lo a chegar na temperatura certa de operação.

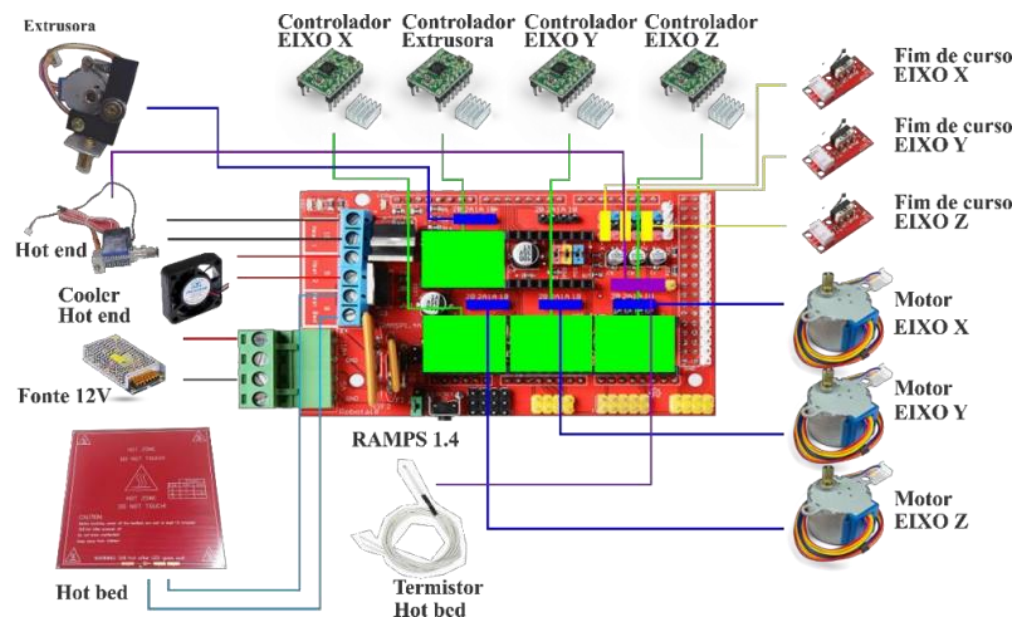

FIGURA 5. Circuito montado na RAMPS 1.4 (Autoria Própria).

\subsubsection{Softwares de impressão $3 d$}

Essa etapa é composta basicamente por três softwares: o Firmware Marlin [22], o software de modelagem e o fatiador. Juntos, eles formam os comandos lógicos do que será impresso.

O Marlin é um programa que dita como o Arduino® irá realizar as operações de funcionamento dos componentes eletrônicos da impressora 3D, foi criado em linguagem C++ e é de código aberto. Para que ele funcione na impressora construída é necessário alterar suas configurações de acordo com as características do projeto, sensores presentes, tipo de placa utilizada, principalmente para que ele faça uma calibração correta das distâncias percorridas. Incialmente, deve-se abrir o código Marlin no software da plataforma Arduinoß e especificar as características da impressora no arquivo Configuration.h. Nele, definiu-se inicialmente qual sensor de temperatura foi utilizado, já que no código possuem diversos tipos de sensores. Em seguida, o tipo de fim de curso escolhido, se ele será utilizado nos mínimos ou máximos e identificando seus limites. Além disso, o firmware conta com uma proteção para a extrusora para que ela não funcione com a hot end fria. Todas as alterações feitas no código estão no Apêndice 2.

Após toda configuração do Marlin, é necessário fazer a calibração da impressora enviando um comando de distância através do software Pronterface para que ele saiba o quanto de filamento (no motor de passos do extrusor) está saindo ou o quanto há de deslocamento (nos motores de passos dos eixos X, Y e Z), em seguida com as medições manuais em um paquímetro, é calculada a escala da quantidade de filamento necessária e a distância percorrida em cada direção. Além da calibração esse software auxilia a verificar as temperaturas e dimensionamento do objeto na hot bed.

Outra etapa de impressão muito importante é o software de modelagem, nele é possível criar as peças no formato .STL. Existem vários softwares de modelagem atualmente, alguns deles pagos, outros gratuitos e alguns com licença para estudantes e professores. Eles variam desde os mais simples de utilizar, aqueles com poucas ferramentas e que só criam peças geométricas, até softwares poderosos capazes de modelar peças orgânicas. A escolha do software de modelagem fica a cargo do projetista, e no projeto atual foi preferível a utilização do AutoCad® por ser de maior familiaridade da equipe e possuir a licença estudantil, porém poderia ser substituído pelo Tinkercad® que é um software online e totalmente gratuito.

Depois de todas estas etapas, nada seria concretizado se não houvesse um software capaz de transformar o objeto modelado em um formato que a impressora entenda. Neste projeto foi utilizado o software específico de uma impressora 3D profissional e de acesso livre, o Slic3r®. Nele é inserido o arquivo em formato .STL, que 
será interpretado e encaminhado para o Arduino, fazendo com que os motores trabalhem juntos e sincronizados, depositando o filamento fundido em seu determinado local. Pode-se dizer que ele é responsável por preparar o objeto para a impressão. O slic3r® divide o objeto modelado em camadas transformando em um arquivo do tipo .GCODE que é o interpretado pela impressora 3D, além disso, ele também estima o tempo de impressão e apresenta a temperatura da hot bed e da hot end. Na Figura 6 as fases de impressão foram resumidas em um fluxograma, onde mostra cada etapa explicada no decorrer do texto.

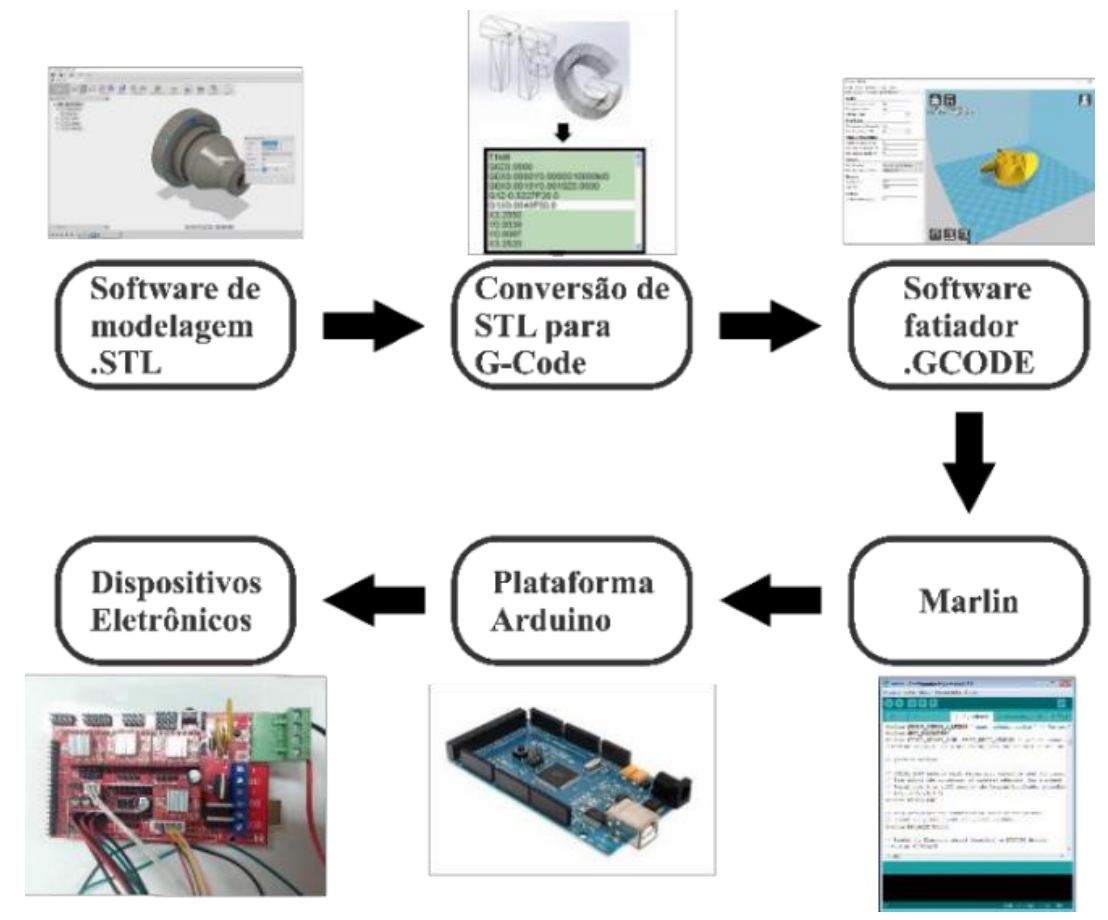

FIGURA 6. Processo de impressão 3D. (Autoria própria)

\section{RESULTADOS E DISCUSSÕES}

A impressora 3D não pôde ser concluída no tempo pré-determinado, devido a fatores externos que atrasaram a montagem e problemas que surgiram no decorrer da construção. Tais problemas trouxeram custos externos ao orçamento inicial, porém, ela continua sendo de baixo custo pois ainda assim seu valor fica bem abaixo das suas semelhantes no mercado. Serão abordados alguns dos principais problemas encontrados durante a montagem e testes, e as medidas adotadas para solucionar os mesmos.

\subsection{Dificuldades mecânicas}

Durante a construção da impressora 3D uma das maiores dificuldades encontradas foi justamente serrar as peças de madeira para que ficassem com as medidas exatas, principalmente porque não se tinha acesso a equipamentos de corte precisos, então todas as peças estruturais de madeira foram feitas manualmente com serras. Isso gerou uma série de erros nos encaixes, como foi o caso, das hastes dos eixos que são acopladas diretamente na madeira, como o furo não ficou milimetricamente perfeito, algumas peças ficaram com folgas e não conseguiam segurar as hastes, nessas situações era necessário que a peça fosse refeita. Além disso, sempre que fosse detectado um erro que fosse prejudicar a resistência mecânica da peça, ela era produzida novamente.

\subsection{Testes de calibração}

Após a finalização da montagem mecânica, eletrônica e as configurações do código, foi realizado o primeiro teste na impressora construída, o teste de calibração dos eixos e do filamento. Ele consiste no cálculo da precisão da resposta dos hardwares aos comandos do software. O procedimento realizado foi utilizando o software Pronterface, onde foi inserido a temperatura da hot end e da hot bed e a área de impressão. A 
impressora respondeu corretamente ao teste, os três eixos se movimentaram e a extrusora expeliu o filamento sem dificuldades. Porém, quando estava sendo finalizado o teste, começou-se a perceber que o Arduino esquentava muito e com pouco tempo depois ele parou de funcionar.

\subsection{Regulador de tensão}

Ao realizar os testes de calibração, foi observado que o Arduino® esquentava muito. Logo, foram iniciados os estudos para detectar o motivo dessa elevação de temperatura e após uma série de medições de corrente e tensões para verificar se estavam dentro dos limites do Arduino®, percebeu-se que que a tensão de alimentação do mesmo era de 13,6 V, ao passo que os limites recomendados eram de 7 a $12 \mathrm{~V}$, ou seja 11,33\% a mais. Com isso foi necessária a adaptação de um regulador de tensão no circuito capaz de ajustar a tensão até que a mesma ficasse dentro dos limites do Arduino®. O dispositivo regulador escolhido foi o LM2596S 2 V 37 V 3 A, mostrado na Figura 7, nele é possível ajustar a tensão de saída através de um potenciômetro que ve acoplado no dispositivo.

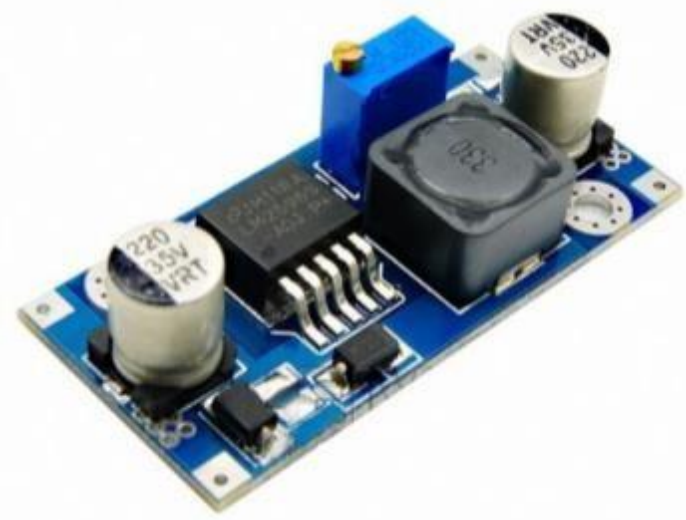

FIGURA 7. Regulador de tensão. [23]

Para a adaptação do regulador de tensão ao circuito, foram colocados quatro fios, um em cada extremidade de entrada e saída, com a finalidade de ligá-lo a RAMPS do Arduino®. Nas entradas In+ e In- foram colocadas aproximadamente $12 \mathrm{~V}$, então, o potenciômetro foi ajustado para que a tensão na saída fosse de $8 \mathrm{~V}$. Embora seja indicada que a diferença de tensão entre a entrada e saída do regulador de tensão seja de $1,5 \mathrm{~V}$, foi inserido uma diferença de $4 \mathrm{~V}$ e não ocorreu nenhuma elevação de temperatura dos componentes nos 20 minutos analisados. Além disso, foi colocado um dissipador de calor sobre o transformador do regulador para protegê-lo caso houvesse uma elevação na temperatura. $\mathrm{O}$ resultado esperado foi obtido com sucesso e na Figura 8 pode ser vista a tensão de 7,9 V medida na saída do regulador de tensão.

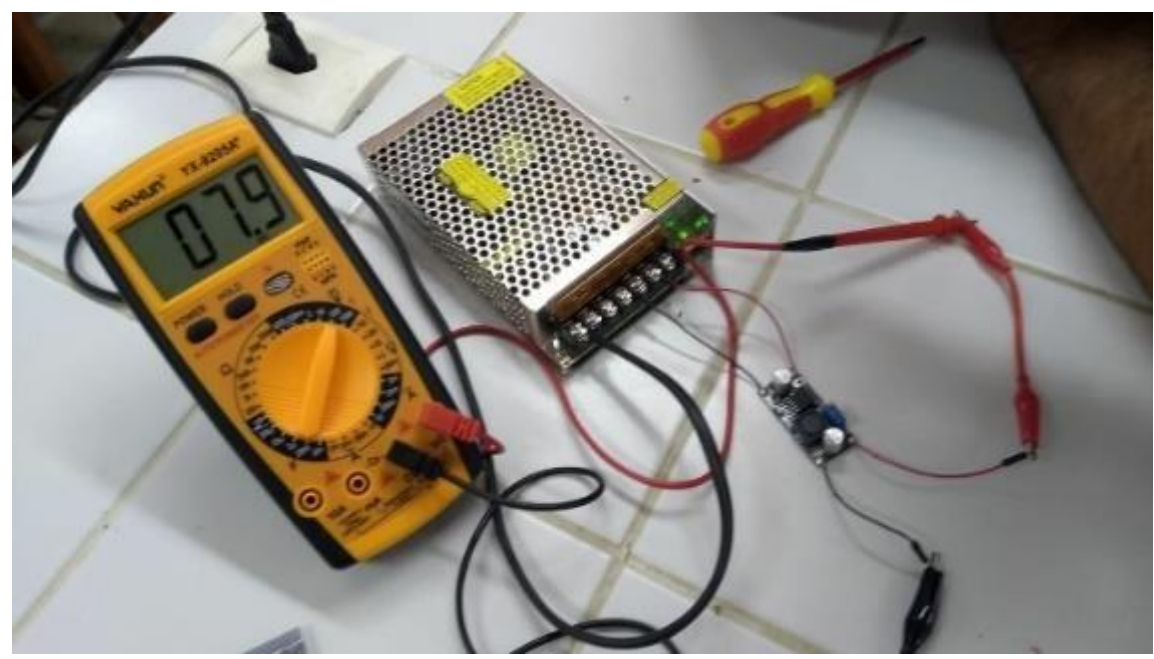

FIGURA 8. Voltagem na saída do regulador de tensão. (Autoria própria) 


\subsection{Estágio atual da impressora $3 d$}

Atualmente a impressora 3D encontra-se com a parte mecânica, extrusora e softwares finalizada e a eletrônica apenas esperando a aquisição da nova plataforma Arduino® para ser acoplado ao sistema, já que a anterior apresentou o defeito no regulador de tensão e queimou. No estágio atual o custo totalizou em R\$ 503,90, já considerando o regulador de tensão e a plataforma nova que foi necessário adquirir. Então, será dado continuação aos testes e futuras impressões. Além disso, estudos estão sendo feitos para possíveis melhorias nos motores e nas estruturas, já que o projeto de pesquisa arrecadou alguns fundos financeiros. Isso irá encarecer um pouco o projeto, porém, os gastos a mais serão compensados com o aprimoramento. O estado atual em que a impressora 3D se encontra é mostrado na Figura 9.

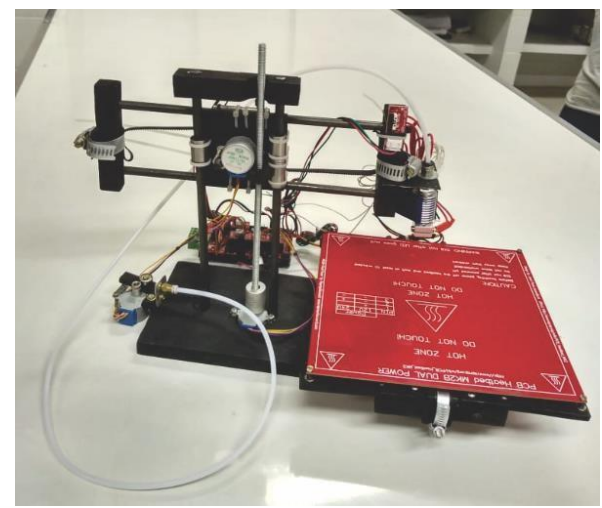

FIGURA 9. Estágio atual da impressora 3D. (Autoria própria)

\section{CONCLUSÕES}

De acordo com os resultados obtidos pode ser visto que tal projeto requer muito conhecimento e precisão na construção, já que a impressora 3D é um instrumento altamente preciso. Devido o Arduino® ser importado, o tempo de entrega no Brasil é longo, logo, o projeto terá continuidade com o recebimento da plataforma. Além disso, nos testes de calibração percebeu-se que os motores de passos adaptados requeriam um esforço muito grande da parte do Arduino®, devido a isso foi pensado como plano futuro a troca dos motores de passos por motores Nema 17 que são próprios para esse fim.

Também são previstas algumas melhorias nas estruturas por consequência da substituição dos motores. Portanto, apesar deste projeto não ter sido finalizado devido ao curto espaço de tempo para construção e problemas que foram aparecendo no decorrer da execução, conseguiu-se trazer resultados satisfatórios, tanto com relação ao aprendizado da equipe quanto a reposta positiva a um dos principais testes de funcionamento, o teste de calibração.

\section{REFERÊNCIAS}

[1] TAKAGAKI, Luiz Koiti. Tecnologia de impressão 3D. Revista Inovação Tecnológica, São Paulo, v.2, n.2. p.2840. jul./dez.2012. Disponível em: <http://doczz.com.br/doc/26444/capitulo-3.-tecnologia-deimpress\%C3\%A3o-3d-luiz-koiti-takagaki>. Acesso em 12 jul. 2017.

[2] FIRMINO, Jórdean et al. MAQUINA DE PROTOTIPAGEM RÁPIDA: IMPRESSORA 3D. 2013 Disponível em: 〈http://sistemaolimpo.org/midias/uploads/2d3ac988c78b4d99f1c40d9f03991a7c.pdf >. Acesso em: 28 ago. 2018.

[3] SOUZA, Elson. Impressora 3D: confira a evolução do dispositivo desde a sua concepção . 2014. Disponível.em: $<$ https://www.techtudo.com.br/noticias/noticia/2014/11/impressora-3d-confira-evolucao-do -dispositivo- desde-sua-concepcao.html>. Acesso em: 30 nov. 2018.

[4] MONK, Simon. Programação com Arduino: Começando com Sketches. [S.1.]: Bookman, 2013. 5 p.

[5] FERREIRA, Géssica da Cruz; KRÜGER, Thaisa Regina; SANTOS, Christiane Bischof dos. UTILIZAÇÃO DA IMPRESSÃO 3D NA MANUFATURA PARA A OTIMIZAÇÃO DE PROCESSOS: UM ESTUDO DE CASO EM INDÚSTRIAS AUTOMOBILÍSTICAS.2016. Disponível em: 
<file:///C:/Users/PESSOAL/Downloads/148-503-1-SM.pdf〉. Acesso em: 28 ago. 2018.

[6] TELES, Vanessa; MORAIS, William A. Impressão 3D . $2016 . \quad$ Disponível em: $\langle$ http://www.cronosquality.com/artigos/ar007.pdf >. Acesso em: 03 jan. 2019.

[7] HORVATH, Joan. Mastering 3D printing: Modeling, Printing, and Prototyping with RepRap-style 3D. Passadena: Apress, 2014.

[8] AGUIAR, L. C. D. Um processo para utilizar a tecnologia de impressão 3D na construção de instrumentos didáticos para o ensino de ciências. Dissertação (Mestrado em Educação para a Ciência) Faculdade de Ciências, UNESP, Bauru, 2016.

[9] WOLFES, R. 3D Printing of Concrete Structures. Graduation Thesis, Eindhoven University of Technology, 2015.

[10] MATOZINHOS, Isabela Penido et al. IMPRESSÃO 3D: INOVAÇÕES NO CAMPO DA MEDICINA. Revista Interdisciplinar Ciências Médicas, Belo Horizonte, v. 1, n. 1, p.143-162, jan. 2017. Disponível

<file:///C:/Users/PESSOAL/Documents/Ufersa/6\%C2\%BA\%20Semestre/TCC/14-40-2-PB.pdf〉. Acesso em: 07 jan. 2019.

[11] MÜLLER, Leonardo. Conheça a Stella, a primeira impressora 3D compacta feita no Brasil . 2016.

Disponível

em:

<https://www.tecmundo.com.br/impressora-3d/111397-conheca-stella-primeira-impressora-3dcompacta-feita-brasil.htm>. Acesso em: 08 jan. 2019.

[12] IMPRESSORA 3D Stella. Disponível em: <https://boaimpressao3d.com.br/shop/impressora3d/impressora- 3d-stella/>. Acesso em: 08 jan. 2019.

[13] ARDUINO Mega Intro. Disponível em: <https://www.instructables.com/id/Arduino-Mega-Intro/>. Acesso em: 07 jan. 2019.

[14] CASTRO, Clarizza Ap. Oliveira et al. A GESTÃo ESTRATÉGICA DE CUSTOS COMO DIFERENCIAL COMPETITIVO PARA MICRO E PEQUENAS EMPRESAS. 2015. Disponível em:

〈http://www.unifia.edu.br/revista_eletronica/revistas/gestao_foco/artigos/ano2015/gest_estrategica_custos.pdf >

. Acesso em: 01 ago. 2018.

[15] FUCK, Marcos Paulo; VILHA, Anapatrícia Morales. Inovação Tecnológica: da definição à ação. Contemporânea: Revista de artes e humanidades, Santo André, p.1-21, out. 2011. Disponível em: 〈http://www.revistacontemporaneos.com.br/n9/dossie/inovacao-tecnologica.pdf $>$. Acesso em: 01 set. 2018.

[16] GOMES, José Ferreira (2014). A tecnologia na sala de aula. Novas tecnologias e educação... Porto: Biblioteca Digital da Faculdade de Letras da Universidade do Porto. Pp. 17-44. Disponível em: 〈http://ler.letras.up.pt/uploads/ficheiros/13290.pdf >. Acesso em: 28 ago. 2018.

[17] PEREIRA, Rosmary Wagner. WEBQUEST - Ferramenta Pedagógica para o Professor. 2008. 52 f. Dissertação (Mestrado) - Curso de Direito, Universidade Tecnológica Federal do Paraná, Paraná, 2009. Cap. 1. Disponível em: $\langle$ http://www.diaadiaeducacao.pr.gov.br/portals/pde/arquivos/1670-8.pdf $>$. Acesso em: 03 set. 2018.

[18] BRASILEIRO, Ada Magali Matias. Manual de produção de textos acadêmicos e científicos. São Paulo: Atlas, 2013.

[19] BUCHA do Rolamento de Esferas para 8mm. [S. 1.], 201-.Disponível

[20] em:https://pt.aliexpress.com/item/WALFRONT-10-p-s-lote-LM8UU-LM12UU-Linear-Motion-B ucha-do- Rolamento-de-Esferas-para-8mm/32835418710.html. Acesso em: 2 jan. 2019.

[21] ROLAMENTOS Rígidos de Esferas Em Uma Carreira. [S. 1.], 201-. Disponível em: https://www.1linha.com.br/rolamentos-rigidos-de-esferas-em-uma-carreira-prod-237.html . Acesso em: 3 jan. 2019.

[22] ABRAÇADEIRAS METÁLICAS. [S. 1.], 201-.Disponível

[23] em:

https://www.todolarmorumbi.com.br/ferragens/abracadeiras-metalicas.html?limit=5\&mod $\mathrm{e}=$ list $\& \mathrm{p}=3$. Acesso em: 3 jan. 2019.

[24] MARLIN. Download. [S. 1.], 201-. Disponível em: http://marlinfw.org/meta/download/. Acesso em: 21 nov. 2018.

[25] AMAZON. RioRand 5 Pack Boost Converter Module XL6009 DC 3.0-30 V to DC 5-35 V Output 
Voltage Adjustable Step up Circuit Board 4A. [S. 1.], 201-. Disponível em: https://www.amazon.com/RioRand-LM2596-

Converter-1-23V-30V-5Pcs-LM2596/dp/B008BHB4L8. Acesso em: 11 fev. 2019. 